\title{
In vitro anti-aging activities of ginkgo biloba leaf extract and its chemical constituents
}

\author{
Xiaoyue WANG ${ }^{1}$, Xiaoyan GONG ${ }^{1}$, Huina $\mathrm{ZHANG}^{1}$, Wanshan $\mathrm{ZHU}^{2}$, Zewu JIANG ${ }^{2}$, Yujing $\mathrm{SHI}^{3}$, $\mathrm{Li} \mathrm{LI}^{1 \star}$ (D)
}

\begin{abstract}
To determine in vitro anti-aging activity and identify the active chemical constituents in Ginkgo leaf extracts. The antioxidant properties of Ginkgo biloba leaves extracts were evaluated using 1,1-diphenyl-2-picrylhydrazyl radical (DPPH) scavenging and 2,2'-azino-bis (3-ethylbenzothiazoline)-6 sulfonic acid radical (ABTS) scavenging assays. The inhibitory effects of extracts and chemical constituents on reactive oxygen species, matrix metalloproteinase-1 (MMP-1) and collagen tpye I level were tested using human dermal fibroblasts (HDFs). Reverse-phase liquid chromatography (RPLC) and ultra-performance liquid chromatography tandem mass spectroscopy (UPLC/MS/MS) were used to quantitatively analyze flavonoids and terpene trilactones in the extraction. The established quantitative analysis method was validated according to the regulatory guidelines. The extraction and compounds kaempferol 3-O- $\beta$-D-glucopyranoside, isorhamnetin-3-O-glucoside, myricetin, ginkgolide A and bilobalide could have potential anti-aging activities of G. biloba. The results suggest that G. biloba could be used as anti-aging products and as a cosmetic and medicinal raw material.
\end{abstract}

Keywords: Ginkgo leaf; antioxidant; matrix metalloproteinase-1; collagen I; chemical analysis.

Practical Application: Research about anti-aging activities and chemicals of Ginkgo biloba.

\section{Introduction}

Skin aging is a complex biological phenomenon due to intrinsic and extrinsic factors. Ultraviolet (UV) exposure causes physical changes in the skin through complex pathways and ultimately results in the generation of reactive oxygen species (ROS) and secretion of matrix metalloproteinases (MMPs) and elastase (Demeule et al., 2000). ROS directly cause skin aging via oxidative damage of lipids, proteins, and DNA of the skin. They can also indirectly induce the production of MMPs via the MAP kinase pathway (Fisher et al., 2002). MMPs are a family of zinc-dependent endopeptidases. MMP-1 is primarily responsible for dermal collagen degradation during the aging process (Kang et al., 2018), and MMP-2 and MMP-9 degrade the extracellular matrix (ECM) proteins that influence skin thickness and wrinkle formation (Lu et al., 2013).

Ginkgo biloba L. (Ginkgoaceae), popularly known as a living fossil (Gong et al., 2008), have been used for 5000 years in traditional Chinese medicine. The leaf extract of G. biloba is composed of flavonoids (24\%), terpene trilactones (6\%), proanthocyanidins, organic acids, and other constituents (Ihl, 2013). The extract has been reported to protect against chronic cerebral hypoperfusion (Kim et al., 2016), improve cognitive function and regulate inflammatory responses (Wan et al., 2016), and prevent UVB-induced photoaging (Chen et al., 2014). Flavonoids are the main contributors to the anti-inflammatory and antioxidant activity of the extract (Baek et al., 2016), whereas terpene trilactones are the main contributors to blood microcirculation and neuroprotective effects (Jiang et al., 2014). In addition, the extract has been demonstrated to be effective in preventing apoptosis and to possess antioxidant activity (Mohanta et al., 2014). However, the relationship between skin anti-aging activity and the chemical constituents in the leaf extract of G. biloba has not been investigated in detail.

The present study was therefore performed to investigate the anti-aging activities of the extraction and main chemical constituents in G. biloba through DPPH, ABTS radical scavenging, ROS scavenging, MMP-1 inhibitory and collagen promoting activities. The chemical constituents in the extraction with anti-aging activity were further elucidated by the established quantitative methods. The results wish to support the use of G. biloba leaf as a raw material in anti-aging cosmetic products in future.

\section{Materials and methods}

\subsection{Chemical and reagents}

Ginkgo leaf was collected from Jiangsu province, China (Pizhou medicinal store). 732 cation adsorption resin and HPD5000 macroporous adsorption resin were purchased from Tianjin Nankai University resin Co., Ltd. (Tianjin, China). 1,1-diphenyl-2-picrylhydrazyl radical (DPPH) and 2,2'-azino-bis (3-ethylbenzo thiazoline)-6 sulfonic acid (ABTS) were obtained from Biodee Biotechnology Co., Ltd. (Beijing, China). MMP-1 Kit (No. I21032323) and collagen I Kit were purchased from CUSABIO. ROS Kit was purchased from Beyotime Biotechnology (No. 01191770503). HPLC-grade acetonitrile was purchased from Merck (Germany). Ultra-pure water (18.2 M $\Omega$ ) was prepared 
with a Milli-Q water purification system (Millipore, Bedford, MA, USA). Rutin (1), quercetin-3-O- $\beta$-glucoside (2), kaempferol 3-O- $\beta$-D-glucopyranoside (3), isorhamnetin-3-O-glucoside (4), myricetin (5), apigenin (6), isoginkgetin (7), ginkgetin (8), ginkgolide A (9), ginkgolide B (10), ginkgolide C (11), ginkgolide $J$ (12), and bilobalide (13) were purchased as reference standards from Beijing Simianti Tech. Co., Ltd. (Beijing, China). All of the reference compounds were determined to be greater than $98 \%$ pure by high-performance liquid chromatography (HPLC) analysis. All other reagents were of analytical grade.

\subsection{Cell culture}

HDFs were purchased from the Cell Bank of the Shanghai Institutes for Biological Sciences, Chinese Academy of Sciences. The cells were cultured in Dulbecco's Modified Eagle Medium (DMEM) supplemented with 10\% fetal bovine serum (FBS; BioWhittaker, Walkersville, MD, USA) and $1 \%$ penicillin-streptomycin (Gibco BRL, NY, USA), at $37^{\circ} \mathrm{C}$ in a humidified atmosphere containing $5 \% \mathrm{CO}_{2}$.

\subsection{Extraction method}

Air-dried samples $(0.1 \mathrm{~kg})$ were sieved and extracted with $1.5 \mathrm{~L}$ of $95 \%$ ethanol $(v / v)$ by ultrasonic extraction for $60 \mathrm{~min}$. In order to remove ginkgolic acids and enrich the active ingredients, the concentrated extraction was eluted through AB-8 macroporous adsorption resin, 732 cation adsorption resin, and HPD5000 macroporous adsorption resin, successively. We got the $60 \%$ ethanol $(v / v)$ elution fraction as the tested extraction. The concentrated dry extract was frozen for use in the following chemical and bioactivity assays.

\subsection{Determination of DPPH radical scavenging activity}

The radical scavenging rates of the samples were measured by the DPPH method (Atta-ur-Rahman et al., 2001). For each sample, an aliquot of $0.5 \mathrm{~mL}$ at different concentrations was added to $1.0 \mathrm{~mL}$ DPPH solution $(100 \mu \mathrm{M})$ for $30 \mathrm{~min}$. Methanol was used as a blank solution. The decrease in absorbance at $517 \mathrm{~nm}$ was measured. DPPH radical scavenging activity was expressed as the percentage (\%) of the original absorbance as follows (Equation 1):

DPPH radical scavenging activity $=\left[\left(\mathrm{A}_{\mathrm{DPPH}}-\mathrm{A}_{\mathrm{S}}\right) / \mathrm{A}_{\mathrm{DPPH}}\right] \times 100$

where $A_{s}$ is the absorbance of the solution after the sample extract has been added and $\mathrm{A}_{\mathrm{DPPH}}$ is the absorbance of the DPPH solution.

\subsection{Determination of ABTS radical scavenging activity}

ABTS was dissolved in water to a $7 \mathrm{mM}$ concentration (Re et al., 1999). ABTS radical cation (ABTS $\left.{ }^{*}\right)$ was produced by reacting ABTS stock solution with $2.45 \mathrm{mM}$ potassium persulfate (final concentration) and allowing the mixture to stand in the dark at $25^{\circ} \mathrm{C}$ for $12-16 \mathrm{~h}$ before use. The ABTS radical cation solution was diluted in ethanol to an absorbance value of $0.70 \pm 0.02$ at $734 \mathrm{~nm}$ and equilibrated at $30^{\circ} \mathrm{C}$. The samples $(0.1 \mathrm{~mL}$; final concentrations of $0.1,0.5,1.0,2.0,4.0$, and $6.0 \mathrm{mg} / \mathrm{mL}$ ) were mixed with $3.9 \mathrm{~mL}$ of diluted ABTS radical cation solution, and the absorbance at $734 \mathrm{~nm}$ was measured after reaction for $6 \mathrm{~min}$.

\subsection{Cell viability assay}

Cell viability and proliferation were evaluated using the 3-(4,5-dimethyl thiazol-2-yl)-2,5-diphenyltetrazolium bromide (MTT) assay (Lee et al., 2006). HDFs were pretreated with the samples at various concentrations. After incubation for $24 \mathrm{~h}$, MTT solution (final concentration: $5 \mathrm{mg} / \mathrm{mL}$ ) was added. Next, the cells were incubated at $37^{\circ} \mathrm{C}$ for $3 \mathrm{~h}$. Finally, the absorbance of each sample was measured on a microplate reader at $570 \mathrm{~nm}$ to obtain the percentage of viable cells.

\subsection{ROS measurement}

The production of peroxides was measured by staining cells with the fluorescent probe 2,7-dichlorofluorescein diacetate (DCFH-DA) (Zhou et al., 2009). This dye is a stable nonpolar compound that readily diffuses into cells and yields DCFH. Intracellular hydrogen peroxide $\left(\mathrm{H}_{2} \mathrm{O}_{2}\right)$ or $\mathrm{OH}$ in the presence of peroxidase changes DCFH to the highly fluorescent compound 2,7-dichlorofluorescein (DCF). Thus, the fluorescence intensity is proportional to the amount of peroxides produced by the cells. After treatment, the cells were harvested, washed with phosphate-buffered saline (PBS: $\mathrm{pH}$ 7.2), and incubated with $10 \mu \mathrm{mol} / \mathrm{L} \mathrm{DCFH}-\mathrm{DA}$ for $0.5 \mathrm{~h}$ at $37^{\circ} \mathrm{C}$. Then, ROS generation was measured by the fluorescence intensity (FL-1, $530 \mathrm{~nm}$ ) of 10,000 cells.

\subsection{Enzyme-linked immunosorbent assay (ELISA) for MMP-1 and collagen types I levels}

Commercially available ELISA kits were performed to measure MMP-1 and collagen I levels (Du et al., 2017). HDFs were cultured in 6-well plates $\left(5 \times 10^{5} / \mathrm{mL}\right.$ cells) with DMEM containing $10 \% \mathrm{FBS}$ for $24 \mathrm{~h}$, after which the medium was replaced with serum-free medium containing the test samples. After incubation for $24 \mathrm{~h}$, the supernatant was collected from each well and MMP-1 and collagen types I levels were measured using ELISA kits. Each sample was analyzed in triplicate.

\subsection{Quantitation of eight flavonoids by HPLC/DAD}

Chromatographic separation was performed using the Agilent 1260LC series system (Agilent Technologies, Palo Alto, CA, USA) equipped with an online vacuum degasser, quaternary pump, autosampler, thermostatted column compartment, and DAD. Agilent Technologies Chemstation software for LC (B.02.01) was used. HPLC separation was performed using the Agilent ZORBAX SB-C18 column $(4.6 \times 250 \mathrm{~mm}, 5 \mu \mathrm{m})$. The detection wavelength was set to $254 \mathrm{~nm}$. The mobile phase consisted of water/phosphoric acid (99.8:0.2, v/v) (A) and acetonitrile (B). The gradient program comprised $15-25 \%$ (B) for 0-25 min, $25-35 \%$ (B) for $25-35 \mathrm{~min}, 35-50 \%$ (B) for $35-45 \mathrm{~min}, 50-60 \%$ (B) for 45-55 min, $60-70 \%$ (B) for $55-60 \mathrm{~min}$, and 70\% (B) for 60-70 min. The flow rate was $0.5 \mathrm{~mL} / \mathrm{min}$. The column temperature was set to $30^{\circ} \mathrm{C}$ and the injection volume was $5.0 \mu \mathrm{L}$. The content of the eight flavonoids (compounds 1 to 8 ) in the active fraction was 
calculated using an appropriate standard curve. Representative chromatograms of the samples are shown in Figure 1.

\subsection{Quantitation of five terpene trilactones by UHPLC/MS/MS}

Chromatographic analysis was performed on ACQUITY ${ }^{\mathrm{TM}}$ UHPLC system (Waters Corp., Milford, MA, USA) with a cooling autosampler and column oven enabling temperature control. The ACQUITY UHPLC ${ }^{\circledast}$ BEH C18 $(2.1 \times 100 \mathrm{~mm}, 1.7 \mu \mathrm{m})$ was employed, and the column temperature was maintained at $40{ }^{\circ} \mathrm{C}$ and a gradient elution with acetonitrile (A)-water $(0.1 \%$ formic acid, B) was used. The gradient program was as follows: 0-0.5 min, $10 \% \mathrm{~A}, 0.5-4.0 \mathrm{~min}, 90 \% \mathrm{~A}$. The flow rate was set at $0.3 \mathrm{~mL} / \mathrm{min}$. The autosampler was conditioned at $10{ }^{\circ} \mathrm{C}$, and the injection volume for analysis was $2.0 \mu \mathrm{L}$. XEVO TQD triple quadruple mass spectrometer (Waters Corp.) equipped with an electrospray ionization source (ESI) was used for mass spectrometric detection. The detection was operated in the multiple reaction monitoring (MRM) mode under unit mass resolution in the mass analyzers. The dwell time was set to 200 $\mathrm{ms}$ for each MRM transition. The MRM transitions were $\mathrm{m} / \mathrm{z}$
$409 \rightarrow 345,425 \rightarrow 361,441 \rightarrow 324,425 \rightarrow 308$, and $325 \rightarrow 163$ for ginkgolide A (9), ginkgolide B (10), ginkgolide C (11), ginkgolide J (12), and bilobalide (13), respectively. After optimization, the source parameters were set as follows: curtain gas, 35 psi; nebulizer gas, 50 psi; turbo gas, 60 psi; ion spray voltage, $3.5 \mathrm{kV}$; and temperature, $500{ }^{\circ} \mathrm{C}$ (Table 1 ). The Masslynx 4.1 software (Waters Corp.) was used for data acquisition and instrument control. Representative chromatograms are shown in Figure 2. Each calibration curve was performed in duplicate, with at least six concentrations of the analyte. The limit of detection (LOD) and limit of quantitation (LOQ) were determined based on S/N ratios of 3:1 and 10:1, respectively.

\subsection{Data analysis}

The statistical significance of the differences between the mean measurements of each treated group and that of the control group were determined using Dunnett's $t$-test. A $p$-value $<0.05$ was considered statistically significant. The data were also analyzed by one-way analysis of variance (ANOVA) using SPSS 17.0 (IBM Corp., Armonk, NY, USA).

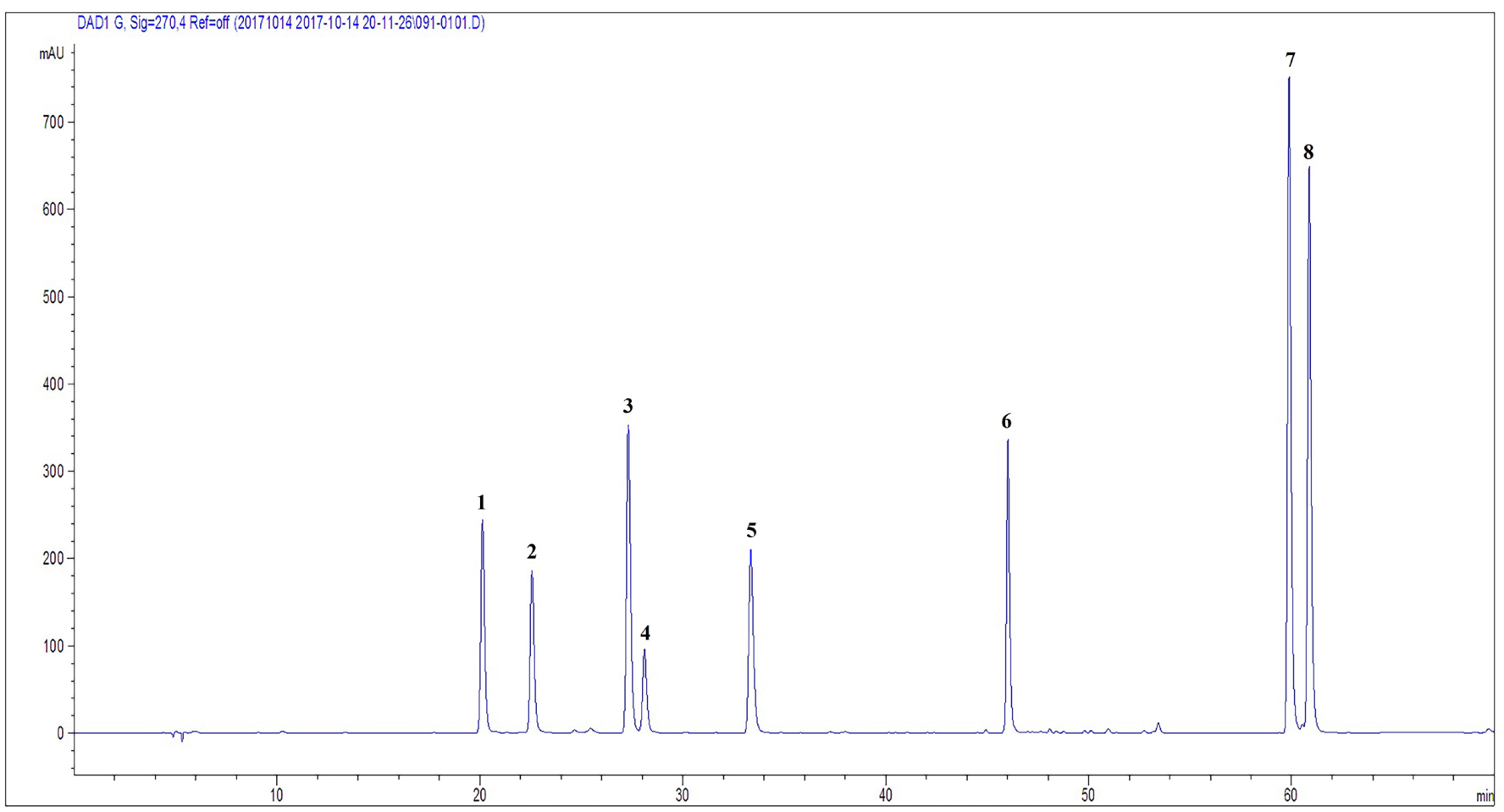

Figure 1. The representative chromatogram of standards rutin (1), quercetin-3-O-beta-glucoside (2), kaempferol-3-O- $\beta$-D-glucopyranoside (3), isorhamnetin-3-O-glucoside (4), myricetin (5), apigenin (6), isoginkgetin (7), ginkgetin (8).

Table 1. The UHPLC/MS/MS conditions of the 5 investigated compounds.

\begin{tabular}{|c|c|c|c|c|c|}
\hline Compounds & Rt (min) & MRM transitions & $\mathrm{CV}(\mathrm{V})$ & $\mathrm{CE}(\mathrm{eV})$ & Ion mode \\
\hline Ginkgolide A & 3.74 & $409 \rightarrow 345$ & 48 & 28 & $\mathrm{ES}^{+}$ \\
\hline Ginkgolide J & 3.22 & $425 \rightarrow 308$ & 50 & 52 & $\mathrm{ES}^{+}$ \\
\hline Ginkgolide B & 3.72 & $425 \rightarrow 361$ & 42 & 30 & $\mathrm{ES}^{+}$ \\
\hline Ginkgolide C & 3.25 & $441 \rightarrow 324$ & 40 & 44 & $\mathrm{ES}^{+}$ \\
\hline Bilobalide & 3.36 & $325 \rightarrow 163$ & 26 & 38 & $\mathrm{ES}^{-}$ \\
\hline
\end{tabular}




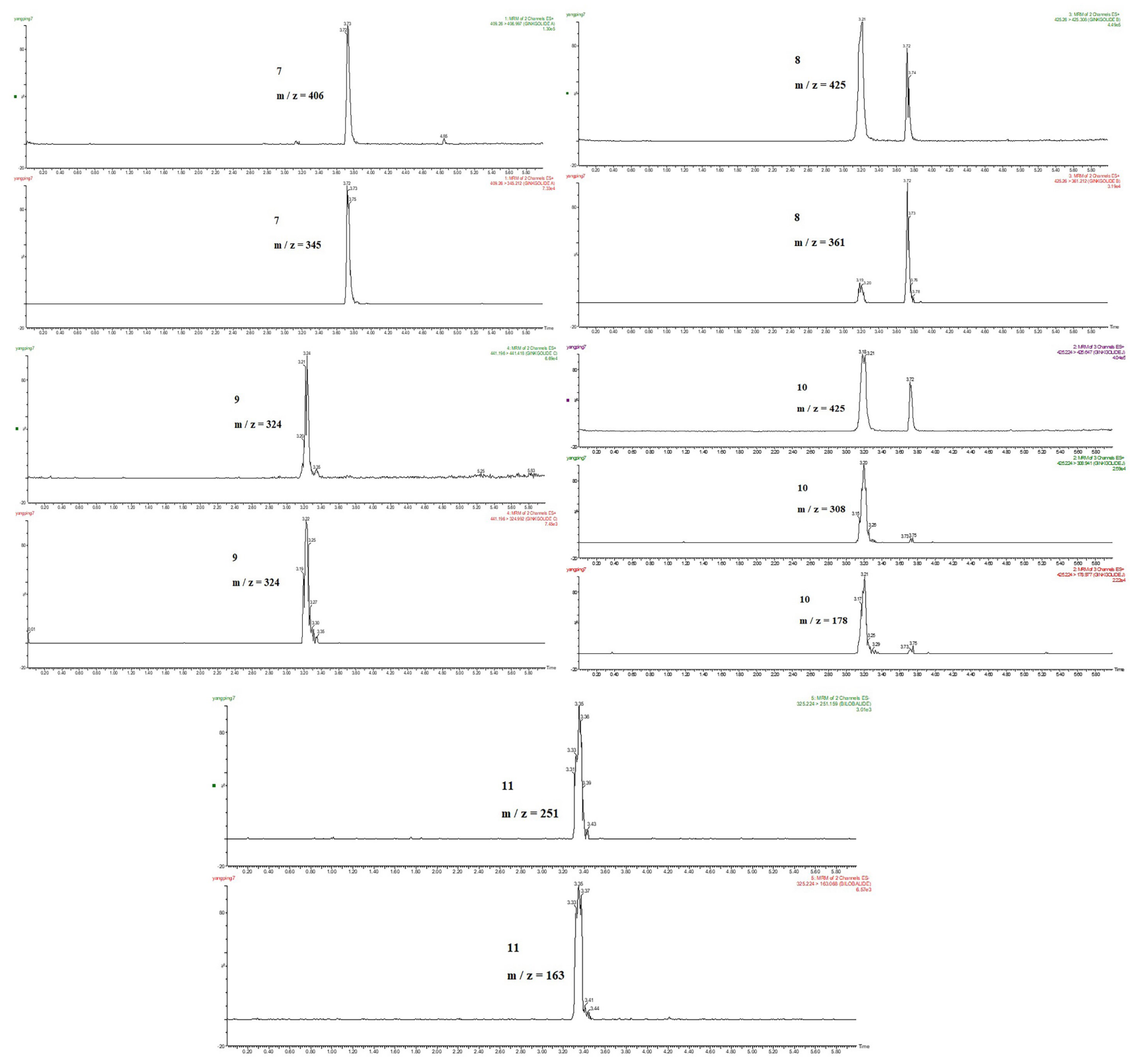

Figure 2. Representative MRM chromatograms of standards and the extraction. Standards: Ginkgolide A (7), Ginkgolide B (8), Ginkgolide C (9), Ginkgolide J (10), Bilobalide (11).

\section{Results and discussion}

\subsection{Antioxidant activities of different extracts}

The results showed that the extraction showed significant DPPH and ABTS radical scavenging activities with IC50 of $0.103 \mathrm{mg} / \mathrm{mL}$ and $0.052 \mathrm{mg} / \mathrm{mL}$. In literature, the extract of G. biloba has been reported to have their potent antioxidant properties. Flavonoids, such as quercetin and kaempferol, can directly quench free radicals (Sadowska-Krępa et al., 2017).

\subsection{Evaluation of the extraction on ROS and MMP-1 in HDFs}

The effects of the extraction against ROS production and MMP- 1 activity were evaluated. MTT assay was used to determine the maximum permissible level (MPL) of the extracts in HDFs at concentrations of $0.125,0.25,0.5$, and $1.0 \mathrm{mg} / \mathrm{mL}$. F0 represents the fluorescence value of the control group, and $\mathrm{F}$ represents the fluorescence value of the sample group, and the greater the $\mathrm{FO} / \mathrm{F}$ ratio, the stronger ROS scavenging ability. At the tested concentration $(0.2 \mathrm{mg} / \mathrm{mL})$, the extraction showed significant ROS scavenging activity $(\mathrm{FO} / \mathrm{F}$ value $1.38 \pm 0.0025)$ compared with the control group (FO/F value $1 \pm 0.043)$, and ROS control group (FO/F value $0.84 \pm 0.023$ ). Moreover, the extraction also showed significant MMP-1 inhibitory activity at the concentration of $0.2 \mathrm{mg} / \mathrm{mL}$ (MMP-1 level $0.22 \pm 0.03 \mathrm{ng} / \mathrm{mL}$ ) and the concentration of $0.1 \mathrm{mg} / \mathrm{mL}$ (MMP-1 level $1.115 \pm 0.25 \mathrm{ng} / \mathrm{mL}$ ) compared with the control group (MMP-1 level $8.98 \pm 0.06 \mathrm{ng} / \mathrm{mL}$ ). ROS are thought to be a major factor in the destruction of collagen, which is a hallmark of photoaging (Dong et al., 2008). The maintenance of structural integrity of the connection between the epidermis 
and dermis, called the dermal-epidermal junction, is important to prevent skin aging (Amano et al., 2005). MMP-1 is considered a key cellular regulator that plays a prominent role in the breakdown of the dermal extracellular matrix, in particular collagen types I and III, during the photoaging process, resulting in collagen deficiency and wrinkling. In vitro studies with cultured HDFs exposed to UV radiation showed an increase in ROS production and a decrease in type I collagen synthesis (Buechner et al., 2008).

\subsection{Validation of the established UHPLC/MS/MS method}

The linearity for each compound was established by plotting the peak area $(y)$ versus the concentration $(x)$ of each analyte, as demonstrated by the equations reported in Table 2. All the calibration curves showed good linearity $\left(r^{2}>0.998\right)$ within the ranges tested. Stability was evaluated by repeated analysis of the same sample solution every $4 \mathrm{~h}$ for $24 \mathrm{~h}$. The results (RSD $<3 \%)$ showed that the sample solution was stable during the analysis. To assess repeatability, six different solutions of the same sample were analyzed. The RSDs were all less than 3\%, which indicates that the method has good repeatability. The LOD (ng), LOQ (ng), precision, and repeatability for all the analytes are summarized in Table 2. The established UHPLC/MS/MS method was identified as a fast, accurate, and suitable method for quantitative analysis of the samples.

\subsection{Quantitative analysis of the main constituents in different fractions}

To elucidate the main chemical constituents responsible for the antioxidant and anti-MMP- 1 activities in the extraction, eight flavonoids (compounds 1 to 8 ) and 5 terpene trilactones (compounds 9 to 13) in the extraction were quantified by the established HPLC/DAD and UHPLC/MS/MS, respectively. The active extraction contained the flavonoids rutin $(1,4.02 \pm 0.022 \mu \mathrm{g} / \mathrm{mg})$, quercetin-3-O- $\beta$-glucoside $(2,1.19 \pm 0.016 \mu \mathrm{g} / \mathrm{mg})$, kaempferol 3-O- $\beta$-D-glucopyranoside ( $3,0.45 \pm 0.003 \mu \mathrm{g} / \mathrm{mg})$, isorhamnetin-3-Oglucoside $(4,0.54 \pm 0.003 \mu \mathrm{g} / \mathrm{mg})$, myricetin $(5,4.71 \pm 0.009 \mu \mathrm{g} / \mathrm{mg})$. These flavonoids are mainly with a glycosidic bond at $\mathrm{C} 3$ position. The main flavonoid myricetin has been reported to have various biological activities, including antioxidant, anticancer (Phillips et al., 2011), anti-inflammatory (Tong et al., 2009), antibacterial (Xu et al., 2001), antiviral (Pasetto et al., 2014), and antidiabetic effects (Li \& Ding, 2012). The terpene trilactones ginkgolide A $(9,10.71 \pm 0.07 \mu \mathrm{g} / \mathrm{mg})$, ginkgolide B $(10,6.54 \pm 0.09 \mu \mathrm{g} / \mathrm{mg})$, ginkgolide C (11, 9.09 $\pm 1.14 \mu \mathrm{g} / \mathrm{mg})$, ginkgolide J $(12,1.49 \pm 0.03 \mu \mathrm{g} / \mathrm{mg})$, and bilobalide $(13,51.56 \pm 2.07 \mu \mathrm{g} / \mathrm{mg})$ were also quantified in the active extraction of G. biloba. The extraction contained $79.39 \mu \mathrm{g} / \mathrm{mg}$ total lactones. Bilobalide was present at relatively higher levels than other lactones. These lactones were reported to have blood microcirculation and neuroprotective effects.

\subsection{Evaluation of the active constituents on MMP-1 and CollageIlevels by ELISA}

To elucidate the active chemical structure with anti-aging activity, we further evaluated the 10 chemical constituents tested in the active extraction on MMP-1 level by ELISA. In HDFs, except for quercetin-3-O- $\beta$-glucoside, the other 9 components showed significant inhibition on MMP- 1 level at concentrations of $0.2 \mathrm{mg} / \mathrm{mL}(p<0.01)$. Kaempferol 3-O- $\beta-D-$ glucopyranoside, isorhamnetin-3-O-glucoside, myricetin, and bilobalide showed significant inhibition on MMP-1 level at a concentration of $0.1 \mathrm{mg} / \mathrm{mL}(p<0.01)$ (Figure 3). In literature, these compounds have been reported to possess significant antioxidant and anti-inflammatory activities (Wu et al., 2016; Ko, 2012). Treatment of isorhamnetin 3-O- $\beta$-D-glucoside in human fibrosarcoma (HT1080) cells significantly inhibited MMP-9 and MMP-2 activities (Kong et al., 2008). Myricetin stimulated procollagen synthesis, and it was proposed that myricetin may utilize signaling mediation through the JNK pathway, a potent inducer of procollagen production (Fisher et al., 2000). In addition, myricetin can downregulate the expression of catalase and superoxide dismutase, the two main enzymes involved in the induction of cellular oxidative stress. Therefore, myricetin is an important material for anti-aging process. Ginkgolide A can also inhibit the expression of MMP-1 at the

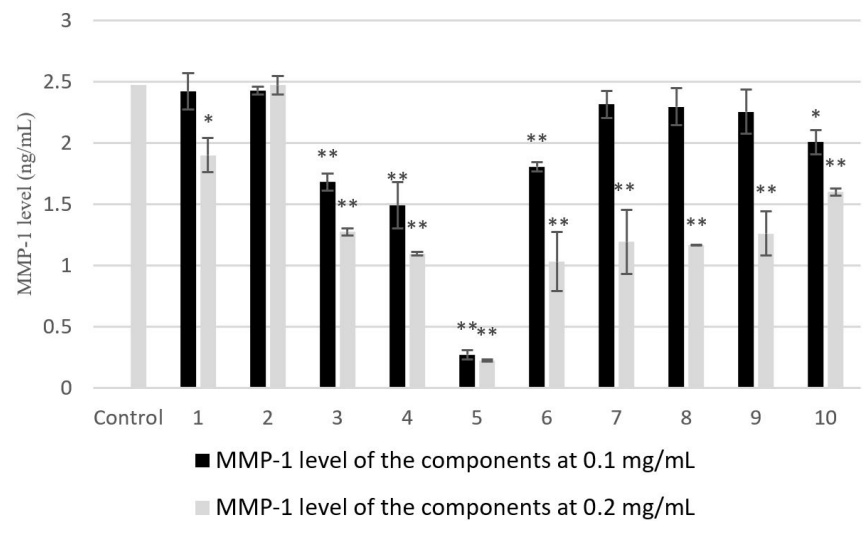

Figure 3. MMP-1 level of the 10 components rutin (1), quercetin-3$\mathrm{O}$ - $\beta$-glucoside (2), kaempferol 3-O- $\beta$-D-glucopyranoside (3), isorhamnetin-3-O-glucoside (4), myricetin (5), ginkgolide A (6), ginkgolide B (7), ginkgolide C (8), ginkgolide J (9), and bilobalide (10). ${ }^{\star}$ indicates significant difference $(\mathrm{p}<0.05)$; ${ }^{\star *}$ indicates very significant difference $(\mathrm{p}<0.01)$.

Table 2. Linear regression data and validation of developed method for 5 investigated compounds.

\begin{tabular}{|c|c|c|c|c|c|c|c|}
\hline Compounds & $\begin{array}{c}\text { Regression } \\
\text { equation }\end{array}$ & $\begin{array}{c}\text { Linear range } \\
(\mu \mathrm{g} / \mathrm{mL})\end{array}$ & $\mathrm{R}^{2}$ & $\begin{array}{c}\mathrm{LOD} \\
(\mathrm{ng} / \mathrm{mL})\end{array}$ & $\begin{array}{c}\text { LOQ } \\
(\mathrm{ng} / \mathrm{mL})\end{array}$ & $\begin{array}{c}\text { Precision } \\
(\mathrm{RSD}, \%, \mathrm{n}=6)\end{array}$ & $\begin{array}{l}\text { Repeatability } \\
(\mathrm{RSD}, \% \mathrm{n}=6)\end{array}$ \\
\hline Ginkgolide A & $y=1494 x+921.6$ & $1-11$ & 0.998 & 15.6 & 52.1 & 2.44 & 2.32 \\
\hline Ginkgolide J & $y=679.6 x+4.598$ & 1-8 & 0.998 & 32.9 & 109.9 & 2.11 & 2.14 \\
\hline Ginkgolide B & $y=188.8 x+112.3$ & $0.2-8$ & 0.998 & 8.7 & 28.9 & 2.15 & 2.35 \\
\hline Ginkgolide C & $y=655.9 x+25.77$ & $0.2-15$ & 0.998 & 45.2 & 150.9 & 2.26 & 2.19 \\
\hline Bilobalide & $y=221.6 x+50.15$ & 5-55 & 0.998 & 49.2 & 163.9 & 2.40 & 2.21 \\
\hline
\end{tabular}




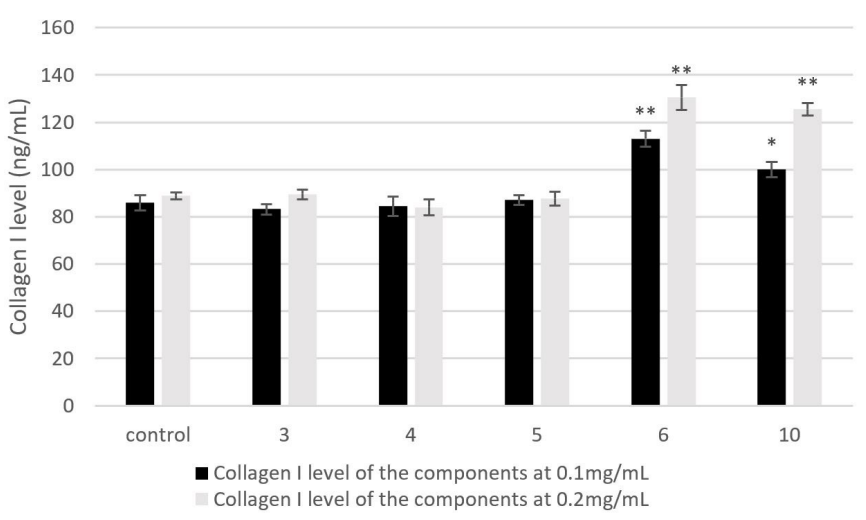

Figure 4. Collagen I level of the 5 components kaempferol 3-O- $\beta$-Dglucopyranoside (3), isorhamnetin-3-O-glucoside (4), myricetin (5), ginkgolide A (6), and bilobalide (10). ${ }^{*}$ indicates significant difference $(\mathrm{p}<0.05) ;{ }^{* *}$ indicates very significant difference $(\mathrm{p}<0.01)$.

concentration of $0.1 \mathrm{mg} / \mathrm{mL}(p<0.05)$. Ginkgolide A reduces inflammatory response in high-glucose-stimulated human umbilical vein endothelial cells through STAT3-mediated pathway (Zhao et al., 2015).

Type I collagen is the major structural component of the ECM and the most abundant protein in skin connective tissue. The individual polypeptide chains of type I collagen are synthesized by dermal fibroblasts from procollagen, which is secreted into the dermal extracellular space. Senescent fibroblasts produce less ECM, such as collagen I and III, and more MMPs, contributing to the observed ageing morphology. In the present study, the effect on Collage I level of the compounds kaempferol 3-O- $\beta$ D-glucopyranoside, isorhamnetin-3-O-glucoside, myricetin, ginkgolide $\mathrm{A}$, and bilobalide were further tested (Figure 4). Ginkgolide A and bilobalide showed better collagen promoting activity than other compounds. We should pay more attentions on the lactones like ginkgolide A and bilobalide about their anti-aging activity in future.

\section{Conclusion}

The results of this study indicate that the extraction of G. biloba, owing to high levels of flavonoids and lactones, inhibited ROS and MMP-1 degradation in HDFs. The chemical constituents kaempferol 3-O- $\beta$-D-glucopyranoside, isorhamnetin-3-Oglucoside, myricetin, ginkgolide $\mathrm{A}$ and bilobalide in the active extraction, showed marked MMP-1 inhibitory activity. Ginkgolide A and bilobalide, which have better collagen promoting activity should be studied further for their anti-aging activity. The results provide evidence supporting the use of the leaf extract and active compounds of G. biloba as the anti-aging medicinal and cosmetic raw materials.

\section{Acknowledgements}

This study was supported by the Key Laboratory of Cosmetic, China National Light Industry, Beijing Technology and Business University Innovation Fund ID: KLC-2017-YB2. This work was also supported by China Cosmetic Collaborative Innovation Center, the Open Research Fund Program of Beijing Key Lab of Plant Resource Research and Development, BTBU(PRRD-2017-ZD1).

\section{References}

Amano, S., Ogura, Y., Akutsu, N., Matsunaga, Y., Kadoya, K., Adachi, E., \& Nishiyama, T. (2005). Protective effect of matrix metalloproteinase inhibitors against epidermal basement membrane damage: skin equivalents partially mimic photoageing process. British Journal of Dermatology, 153(s2, Suppl. 2), 37-46. http://dx.doi.org/10.1111/j.13652133.2005.06968.x. PMid:16280020.

Baek, S. H., Lee, J. H., Ko, J., Lee, H., Nam, D., Lee, S. G., Yang, W. M., Um, J., Lee, J., Kim, S., Shim, B. S., \& Ahn, K. S. (2016). Ginkgetin Blocks Constitutive STAT3 Activation and Induces Apoptosis through Induction of SHP-1 and PTEN Tyrosine Phosphatases. Phytotherapy Research, 30(4), 567-576. http://dx.doi.org/10.1002/ ptr.5557. PMid:27059688.

Buechner, N., Schroeder, P., Jakob, S., Kunze, K., Maresch, T., Calles, C., Krutmann, J., \& Haendeler, J. (2008). Changes of MMP-1 and collagen type I $\alpha 1$ by UVA, UVB and IRA are differentially regulated by Trx-1. Experimental Gerontology, 43(7), 633-637. http://dx.doi. org/10.1016/j.exger.2008.04.009. PMid:18524517.

Chen, C., Chiang, A., Liu, H., \& Chang, Y. (2014). EGb-761 prevents ultraviolet B-induced photoaging via inactivation of mitogen-activated protein kinases and proinflammatory cytokine expression. Journal of Dermatological Science, 75(1), 55-62. http://dx.doi.org/10.1016/j. jdermsci.2014.04.001. PMid:24802711.

Demeule, M., Brossard, M., Page, M., Gingras, D., \& Beliveau, R. (2000). Matrix metalloproteinase inhibition by green tea catechins. Biochimica et Biophysica Acta, 1478(1), 51-60. http://dx.doi.org/10.1016/S01674838(00)00009-1. PMid:10719174.

Dong, K. K., Damaghi, N., Picart, S. D., Markova, N. G., Obayashi, K., Okano, Y., Masaki, H., Grether-Beck, S., Krutmann, J., Smiles, K. A., \& Yarosh, D. B. (2008). UV-induced DNA damage initiates release of MMP-1 in human skin. Experimental Dermatology, 17(12), 1037-1044. http://dx.doi.org/10.1111/j.1600-0625.2008.00747.x. PMid:18459971.

Du, G., Chen, W., Li, X., He, R., \& Feng, P. (2017). Induction of MMP-1 and -3 by cyclical mechanical stretch is mediated by IL- 6 in cultured fibroblasts of keratoconus. Molecular Medicine Reports, 15(6), 38853892. http://dx.doi.org/10.3892/mmr.2017.6433. PMid:28393195.

Fisher, G. J., Datta, S., Wang, Z., Li, X. Y., Quan, T., Chung, J. H., Kang, S., \& Voorhees, J. J. (2000). c-Jun-dependent inhibition of cutaneous procollagen transcription following ultraviolet irradiation is reversed by all-trans retinoic acid. The Journal of Clinical Investigation, 106(5), 663-670. http://dx.doi.org/10.1172/JCI9362. PMid:10974019.

Fisher, G. J., Kang, S., Varani, J., Bata-Csorgo, Z., Wan, Y., Datta, S., \& Voorhees, J. J. (2002). Mechanisms of Photoaging and Chronological Skin Aging. Archives of Dermatology, 138(11), 1462-1470. http:// dx.doi.org/10.1001/archderm.138.11.1462. PMid:12437452.

Gong, W., Chen, C., Dobeš, C., Fu, C., \& Koch, M. A. (2008). Phylogeography of a living fossil: Pleistocene glaciations forced Ginkgo biloba L. (Ginkgoaceae) into two refuge areas in China with limited subsequent postglacial expansion. Molecular Phylogenetics and Evolution, 48(3), 1094-1105. http://dx.doi.org/10.1016/j. ympev.2008.05.003. PMid:18554931.

Ihl, R. (2013). Effects of Ginkgo biloba extract EGb $761^{\circ}$ in dementia with neuropsychiatric features: review of recently completed randomised, controlled trials. International Journal of Psychiatry in Clinical Practice, 17(Suppl. 1), 8-14.

Jiang, M., Li, J., Peng, Q., Liu, Y., Liu, W., Luo, C., Peng, J., Li, J., Yung, K. K. L., \& Mo, Z. (2014). Neuroprotective effects of bilobalide on cerebral ischemia and reperfusion injury are associated with inhibition of pro-inflammatory mediator production and down-regulation of 
JNK1/2 and p38 MAPK activation. Journal of Neuroinflammation, 11(1), 167. http://dx.doi.org/10.1186/s12974-014-0167-6. PMid:25256700.

Kang, C. H., Rhie, S. J., \& Kim, Y. C. (2018). Antioxidant and Skin Anti-Aging Effects of Marigold Methanol Extract. Toxicological Research,34(1), 31-39. http://dx.doi.org/10.5487/TR.2018.34.1.031. PMid:29371999.

Kim, M., Bang, J. H., Lee, J., Han, J., Baik, T. G., \& Jeon, W. K. (2016). Ginkgo biloba L. extract protects against chronic cerebral hypoperfusion by modulating neuroinflammation and the cholinergic system. Phytomedicine, 23(12), 1356-1364. http://dx.doi.org/10.1016/j. phymed.2016.07.013. PMid:27765355.

Ko, S. (2012). Myricetin suppresses LPS-induced MMP expression in human gingival fibroblasts and inhibits osteoclastogenesis by downregulating NFATc1 in RANKL-induced RAW 264.7 cells. Archives of Oral Biology, 57(12), 1623-1632. http://dx.doi.org/10.1016/j. archoralbio.2012.06.012. PMid:22795564.

Kong, C., Kim, Y. A., Kim, M., Park, J., Kim, J., Kim, S., Lee, B., Nam, T. J., \& Seo, Y. (2008). Flavonoid glycosides isolated from Salicornia herbacea inhibit matrix metalloproteinase in HT1080 cells. Toxicology In Vitro, 22(7), 1742-1748. http://dx.doi.org/10.1016/j.tiv.2008.07.013. PMid:18715546.

Lee, M., Lin, Y., Hsu, F., Zhan, G., \& Yen, K. (2006). Bioactive constituents of Spatholobus suberectus in regulating tyrosinase-related proteins and mRNA in HEMn cells. Phytochemistry, 67(12), 1262-1270. http://dx.doi.org/10.1016/j.phytochem.2006.05.008. PMid:16782143.

Li, Y., \& Ding, Y. (2012). Minireview: Therapeutic potential of myricetin in diabetes mellitus. Food Science and Human Wellness, 1(1), 19-25. http://dx.doi.org/10.1016/j.fshw.2012.08.002.

Lu, C., Kim, B. M., Lee, D., Lee, M. H., Kim, J. H., Pyo, H., \& Chai, K. Y. (2013). Synthesis of lipoic acid-peptide conjugates and their effect on collagen and melanogenesis. European Journal of Medicinal Chemistry, 69, 449-454. http://dx.doi.org/10.1016/j. ejmech.2013.09.011. PMid:24090916.

Mohanta, T. K., Tamboli, Y., \& Zubaidha, P. K. (2014). Phytochemical and medicinal importance of Ginkgo biloba L. Natural Product Research, 28(10), 746-752. http://dx.doi.org/10.1080/14786419.20 13.879303. PMid:24499319.

Pasetto, S., Pardi, V., \& Murata, R. M. (2014). Anti-HIV-1 Activity of Flavonoid Myricetin on HIV-1 Infection in a Dual-Chamber In Vitro Model. PLoS One, 9(12), e115323. http://dx.doi.org/10.1371/ journal.pone.0115323. PMid:25546350.

Phillips, P. A., Sangwan, V., Borja-Cacho, D., Dudeja, V., Vickers, S. M., \& Saluja, A. K. (2011). Myricetin induces pancreatic cancer cell death via the induction of apoptosis and inhibition of the phosphatidylinositol 3-kinase (PI3K) signaling pathway. Cancer Letters, 308(2), 181-188. http://dx.doi.org/10.1016/j.canlet.2011.05.002. PMid:21676539.

Rahman, A. U., Choudhary, M. I., \& Thomson, W. J. (2001). Bioassay techniques for drug development. Netherlands: Harwood Academic Publishers.

Re, R., Pellegrini, N., Proteggente, A., Pannala, A., Yang, M., \& RiceEvans, C. (1999). Antioxidant activity applying an improved ABTS radical cation decolorization assay. Free Radical Biology \& Medicine, 26(9), 1231-1237. http://dx.doi.org/10.1016/S0891-5849(98)003153. PMid:10381194.

Sadowska-Krępa, E., Kłapcińska, B., Pokora, I., Domaszewski, P., Kempa, K., \& Podgórski, T. (2017). Effects of six-week ginkgo biloba supplementation on aerobic performance, blood pro/antioxidant balance, and serum brain-derived neurotrophic factor in physically active men. Nutrients, 9(8), 803. http://dx.doi.org/10.3390/nu9080803. PMid:28933745.

Tong, Y., Zhou, X., Wang, S., Yang, Y., \& Cao, Y. (2009). Analgesic activity of myricetin isolated from Myrica rubra Sieb. et Zucc. leaves. Archives of Pharmacal Research, 32(4), 527-533. http://dx.doi.org/10.1007/ s12272-009-1408-6. PMid:19407970.

Wan, W., Zhang, C., Danielsen, M., Li, Q., Chen, W., Chan, Y., \& Li, Y. (2016). EGb761 improves cognitive function and regulates inflammatory responses in the APP/PS1 mouse. Experimental Gerontology, 81, 92 100. http://dx.doi.org/10.1016/j.exger.2016.05.007. PMid:27220811.

Wu, Z., Zheng, X., Gong, M., \& Li, Y. (2016). Myricetin, a potent natural agent for treatment of diabetic skin damage by modulating TIMP/ MMPs balance and oxidative stress. Oncotarget, 7(44), 71754-71760. http://dx.doi.org/10.18632/oncotarget.12330. PMid:27765936.

Xu, H., Ziegelin, G., Schroder, W., Frank, J., Ayora, S., Alonso, J. C., Lanka, E., \& Saenger, W. (2001). Flavones inhibit the hexameric replicative helicase RepA. Nucleic Acids Research, 29(24), 50585066. http://dx.doi.org/10.1093/nar/29.24.5058. PMid:11812837.

Zhao, Q., Gao, C., \& Cui, Z. (2015). Ginkgolide A reduces inflammatory response in high-glucose-stimulated human umbilical vein endothelial cells through STAT3-mediated pathway. International Immunopharmacology, 25(2), 242-248. http://dx.doi.org/10.1016/j. intimp.2015.02.001. PMid:25681539.

Zhou, Y., Zhang, S., Liu, C., \& Cai, Y. (2009). The protection of selenium on ROS mediated-apoptosis by mitochondria dysfunction in cadmium-induced LLC-PK1 cells. Toxicology In Vitro, 23(2), 288294. http://dx.doi.org/10.1016/j.tiv.2008.12.009. PMid:19135140. 